PEDRO IGOR MANTOAN

\title{
O FEDERALISMO FISCAL BRASILEIRO E A EXPERIÊNCIA DO FUNDEB: APLICAÇÃO DO MODELO DE EQUALIZAÇÃO FISCAL
}

\author{
Dissertação de Mestrado
}

Orientador Professor Titular Dr. Fernando Facury Scaff

UNIVERSIDADE DE SÃO PAULO

FACULDADE DE DIREITO

SÃO PAULO-SP

2019 



\title{
PEDRO IGOR MANTOAN
}

\section{O FEDERALISMO FISCAL BRASILEIRO E A EXPERIÊNCIA DO FUNDEB: APLICAÇÃO DO MODELO DE EQUALIZAÇÃO FISCAL}

\begin{abstract}
Dissertação de Mestrado, apresentada à banca examinadora do Programa de Pós-Graduação em Direito, da Faculdade de Direito da Universidade de São Paulo, como exigência parcial para a obtenção do título de Mestre em Direito, na área de concentração Direito Econômico e Financeiro, sob orientação do Professor Titular Dr. Fernando Facury Scaff.
\end{abstract}

UNIVERSIDADE DE SÃO PAULO

FACULDADE DE DIREITO

SÃO PAULO-SP

2019 
MANTOAN, Pedro Igor.

O Federalismo Fiscal Brasileiro e a experiência do FUNDEB: aplicação do modelo de Equalização Fiscal. Dissertação de Mestrado.

Orientador: Professor Titular Dr. Fernando Facury Scaff. Universidade de São Paulo, Faculdade de Direito, Departamento de Direito Econômico e Financeiro.

1. Federalismo Fiscal. 2. Desigualdades Regionais. 3. Equalização Fiscal. 4. Fundos Públicos. 


\section{PEDRO IGOR MANTOAN}

\section{O FEDERALISMO FISCAL BRASILEIRO E A EXPERIÊNCIA DO FUNDEB: APLICAÇÃO DO MODELO DE EQUALIZAÇÃO FISCAL}

BANCA EXAMINADORA:

Professor Titular Dr. Fernando Facury Scaff - Orientador.

Instituição: USP - Faculdade de Direito.

Assinatura:

Professor:

Instituição: . Assinatura:

Professor:

Instituição: . Assinatura:

Professor:

Instituição: . Assinatura:

Julgamento: 



\section{AGRADECIMENTOS}

A presente pesquisa não seria possível sem o empenho do Professor Titular Dr. Fernando Facury Scaff, a quem tenho enorme gratidão pela orientação empreendida durante esses três anos. Foi um período de intensas reflexões sobre o Direito Financeiro e, mais especificamente, sobre os desafios do Federalismo Fiscal Brasileiro.

O esforço empreendido no presente trabalho foi motivado pela visão de um Direito Financeiro que supere o formalismo e tenha sua aplicação dirigida pelos objetivos consagrados na Constituição Federal, lição aprendida com o Professor Scaff. Verdadeiro privilégio poder contar com sua orientação. Serei eternamente grato por suas aulas, suas indicações e, sobretudo, seus alertas e correções acerca dos rumos do trabalho.

Enorme gratidão também ao Professor Titular Dr. Heleno Taveira Torres, que desde os tempos de graduação é para mim um importante conselheiro, sendo o responsável por minha escolha pelo Direito Financeiro como campo de pesquisa acadêmica. Professor Heleno sempre demonstrou enorme preocupação com a relação entre o Direito e as questões sociais, políticas e econômicas do país. Seu engajamento nos grandes problemas nacionais foi importante motivação para a realização deste trabalho.

Qualquer esforço, todavia, não seria remotamente viável sem anos de sacrifício realizado por meus pais, Ruth e Pedro. Se foi possível a jornada até a realização do Mestrado em Direito no Largo de São Francisco, isso foi graças ao sacrifício deles, que tudo fizeram para propiciar que eu e João tivéssemos as melhores condições de vida. Com eles aprendemos a importância da educação. Sobretudo, aprendemos desde cedo que nem todas as famílias têm a oportunidade de alcançar as mesmas condições sociais e que devemos contribuir como possível para que isso seja revertido.

Que esta pesquisa possa colaborar ao menos com uma migalha ao debate brasileiro sobre a desigualdade e as formas de sua superação. 



\section{RESUMO}

MANTOAN, Pedro Igor. O Federalismo Fiscal Brasileiro e a experiência do FUNDEB: aplicação do modelo de Equalização Fiscal. 180 p. Mestrado - Faculdade de Direito, Universidade de São Paulo. São Paulo. 2019.

A presente pesquisa visa analisar a forma pela qual os critérios atualmente vigentes de compartilhamento federativo das riquezas nacionais se relacionam com as desigualdades regionais do país. Parte-se de um diagnóstico acerca da situação do Federalismo Fiscal Brasileiro, analisando-se a forma de rateio adotada no país: rateio de fontes de arrecadação e rateio do produto arrecadado. Na forma de rateio de fontes, buscase analisar seu mecanismo diante da realidade percebida e possibilidade de realização econômica da autonomia política pretendida pelo federalismo. No rateio do produto da arrecadação, subdividem-se a repartição direta de receitas tributárias e a repartição indireta por meio de fundos. Destaca-se ainda a forma de rateio da receita patrimonial decorrente da exploração de recursos naturais não renováveis. Verifica-se, a partir de tal análise, a insuficiência do mecanismo de rateio para o cumprimento dos objetivos constitucionais de cooperação federativa e superação das desigualdades regionais. Diante de tal constatação, busca-se o aprimoramento dos critérios vigentes a partir do exame do modelo experimentado pelo Fundo de Manutenção e Desenvolvimento da Educação Básica (FUNDEB), o qual insere no ordenamento brasileiro o critério de Equalização Fiscal como parâmetro alocativo, interagindo vinculação de receita com transferências intergovernamentais e execução integrada de políticas públicas nos três níveis federativos. Busca-se, então, a partir da experiência do FUNDEB avaliar a aplicabilidade do modelo de Fundo de Equalização para a realidade brasileira, de modo a se implementar a equidade como critério norteador das relações federativas no país.

Palavras-chave: Federalismo Fiscal; transferências intergovernamentais; desigualdades regionais; Fundos de Participação; Fundos de Destinação; Fundos de Equalização; FUNDEB. 



\begin{abstract}
MANTOAN, Pedro Igor. Brazilian Fiscal Federalism and the FUNDEB experience: fiscal equalization model application. 180 p. Master - Faculty of Law, São Paulo University. São Paulo. 2019.

The present research aims to analyze how the current criteria of federative sharing of the national wealthy are related to regional inequalities of the country. It is based on a diagnosis about the Brazilian Fiscal Federalism condition, examining the form of distribution implemented by the country: revenue sources apportionment and proceeds collected apportionment. In the revenue sources apportionment, it is sought to analyze its mechanism according to the perceived reality and economic realization possibility of the political autonomy sought by federalism. In the proceeds collected apportionment, a subdivision: the direct distribution of tax revenues and the indirect allocation through funds. It also highlights the form of apportionment of the income from nonrenewable natural resources exploitation. Through this analysis, the insufficiency of apportionment mechanism to fulfill the constitutional objectives of federative cooperation and regional inequalities overcoming is verified. According to that, it is sought to improve the current criteria by examining the model attempted by Basic Education Maintenance and Development Fund (FUNDEB), which inserts in Brazilian system the Fiscal Equalization criteria as an allocative parameter of revenues from intergovernmental transfers and integrated implementation of public policies at the three federative levels. It is pursued, therefore, from FUNDEB experience to evaluate the Equalization Fund model applicability to Brazilian reality, in order to implement equity as a guiding criterion of the federative relations in the country.
\end{abstract}

Keywords: Fiscal Federalism; intergovernmental transfers; region inequalities; Participation Funds; Destination Funds; Equalization Funds; FUNDEB. 



\section{LISTA DE ABREVIATURAS E SIGLAS}

ACO: Ação Cível Originária

ADCT: Ato das Disposições Constitucionais Transitórias

ADI: Ação Direta de Inconstitucionalidade

ADO: Ação Direita de Inconstitucionalidade por Omissão

CF: Constituição Federal

CFEM: Compensação Financeira sobre a Exploração Mineral

CFURH: Compensação Financeira pela Utilização de Recursos Hídricos

CIDE: Contribuição de Intervenção no Domínio Econômico

CNS: Conselho Nacional de Saúde

COFINS: Contribuição para o Financiamento da Seguridade Social

CPMF: Contribuição Provisória sobre Movimentação Financeira

CSLL: Contribuição Social sobre o Lucro Líquido

CTN: Código Tributário Nacional

DF: Distrito Federal

DNPM: Departamento Nacional de Produção Mineral

DRE: Desvinculação de Receitas dos Estados

DRM: Desvinculação de Receitas dos Municípios

DRU: Desvinculação de Receitas da União

EC: Emenda Constitucional 
FNDCT: Fundo Nacional de Desenvolvimento Científico e Tecnológico

FNS: Fundo Nacional de Saúde

FNSP: Fundo Nacional de Segurança Pública

FPE: Fundo de Participação dos Estados e Distrito Federal

FPM: Fundo de Participação dos Municípios

FUNDEB: Fundo de Manutenção e Desenvolvimento da Educação Básica e Valorização dos

Profissionais da Educação

FUNDEF: Fundo de Manutenção e Desenvolvimento do Ensino Fundamental e Valorização do Magistério

FUNPEN: Fundo Penitenciário Nacional

IBAMA: Instituto Brasileiro do Meio Ambiente e dos Recursos Naturais Renováveis

ICMS: Imposto sobre Circulação de Mercadorias e Serviços

INEP: Instituto Nacional de Estudos e Pesquisas Educacionais Anísio Teixeira

IOF: Imposto sobre Operações Crédito, Câmbio e Seguro, ou relativas a Títulos ou Valores Mobiliários

IPCA: Índice de Preços ao Consumidor Amplo

IPI: Imposto sobre Produtos Industrializados

IPTU: Imposto sobre a Propriedade Predial e Territorial Urbana

IPVA: Imposto sobre a Propriedade de Veículos Automotores

IR: Imposto de Renda e Proventos de Qualquer Natureza

ISS: Imposto sobre Serviços

ITBI: Imposto sobre Transmissão Inter Vivos

ITCMD: Imposto sobre Transmissão Causa Mortis e Doações 
ITR: Imposto sobre a Propriedade Territorial Rural

IVA: Imposto de Valor Agregado

LDO: Lei de Diretrizes Orçamentárias

LOA: Lei Orçamentária Anual

LRF: Lei de Responsabilidade Fiscal

PEC: Proposta de Emenda Constitucional

PIB: Produto Interno Bruto

STF: Supremo Tribunal Federal

STN: Secretaria do Tesouro Nacional

SUS: Sistema Único de Saúde

SUSP: Sistema Único de Segurança Pública

TCE: Tribunal de Contas do Estado

TCU: Tribunal de Contas da União 



\section{SUMÁRIO}

INTRODUÇÃO.

1. DESAFIOS DO FEDERALISMO FISCAL BRASILEIRO …...............................2 25

1.1. Federalismo Cooperativo na Constituição.................................................... 27

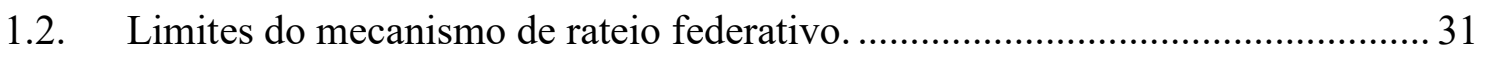

1.2.1. Dinâmica do rateio das fontes de arrecadação. ................................................ 32

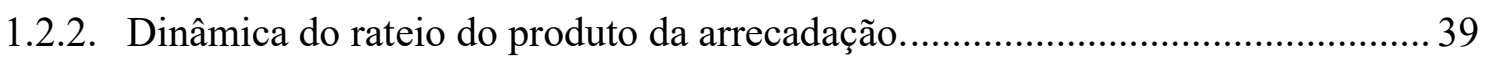

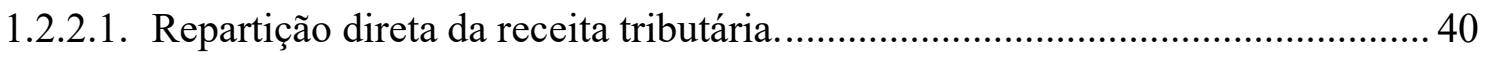

1.2.2.2. Repartição indireta via Fundos de Participação. ............................................. 42

1.2.2.2.1. Fundo de Participação dos Estados......................................................... 43

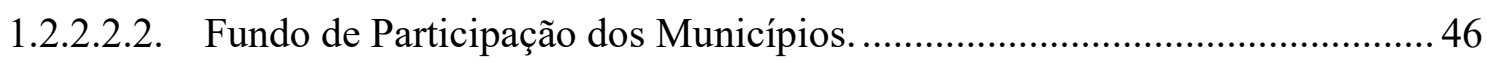

1.2.2.3. Transferência e vinculação da receita patrimonial. ........................................ 48

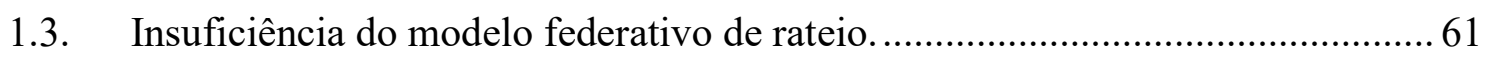

1.3.1. Matriz econômica e capacidade de arrecadação local. ...................................... 61

1.3.2. Concentração de recursos no ente central e a "brecha" vertical. ........................ 64

1.3.3. Distorção federativa sobre a desvinculação de receitas.................................... 65

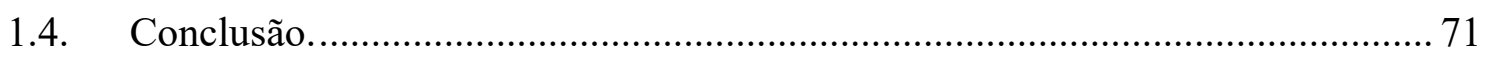

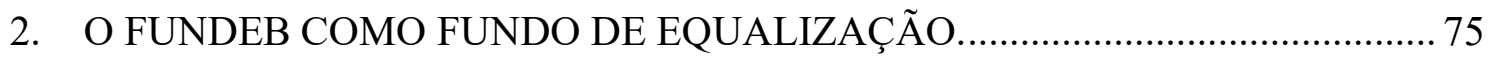

2.1. Fundos Públicos como instrumento de vinculação de receita............................ 76

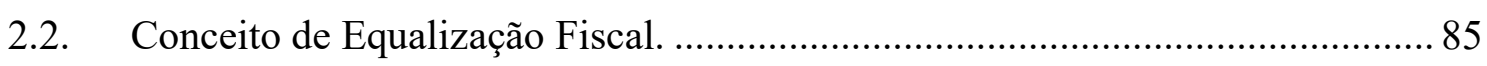

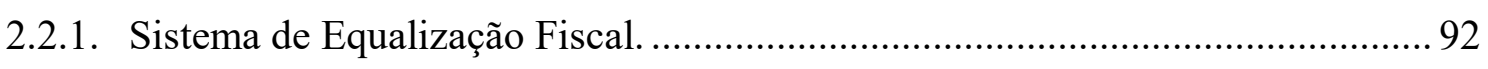

2.3. O modelo do FUNDEB para vinculação e transferência federativa. ................... 96

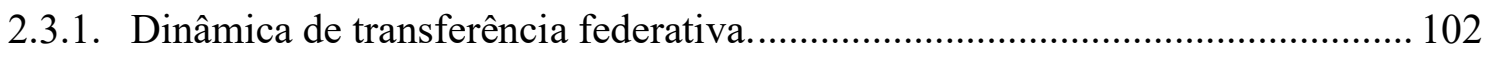

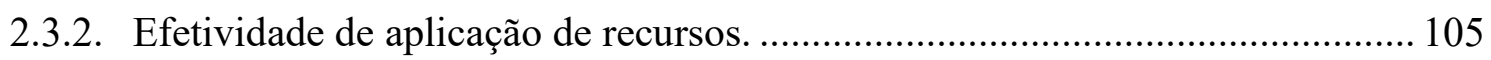

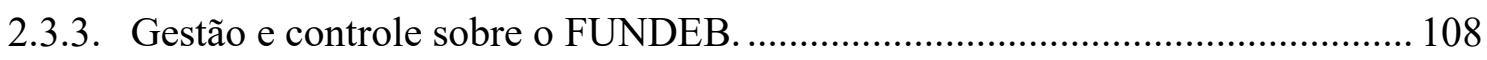


2.4. Conclusão.

3. APLICABILIDADE DO MODELO DE EQUALIZAÇÃO FISCAL..................... 117

3.1. Equalização como Paradigma ao Federalismo Cooperativo............................. 117

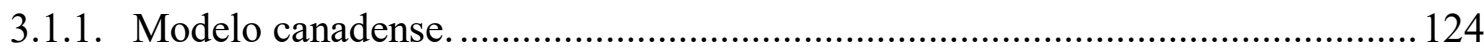

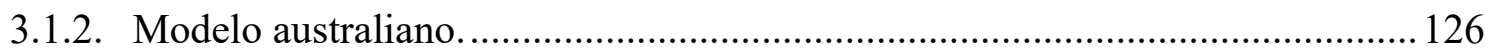

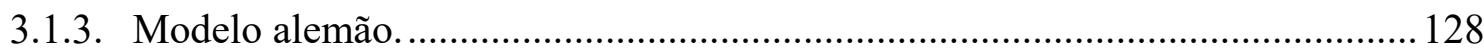

3.2. Adequação do Modelo de Fundo de Equalização Fiscal.................................... 130

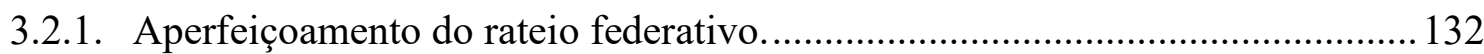

3.2.2. Vinculação de receita e a "cesta básica de serviços". ........................................ 135

3.2.3. Implementação do Fundo de Equalização Fiscal. ............................................... 144

3.3. Responsabilidade fiscal, direitos fundamentais e Equalização. ......................... 147

3.3.1. Contingenciamento dos recursos vinculados dos Fundos............................... 148

3.3.2. Novo Regime Fiscal e as vinculações constitucionais.................................... 151

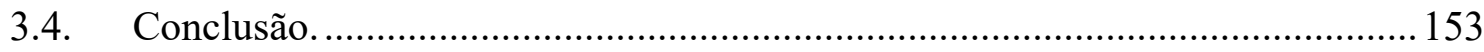

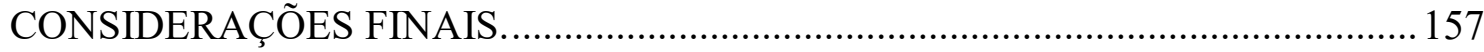

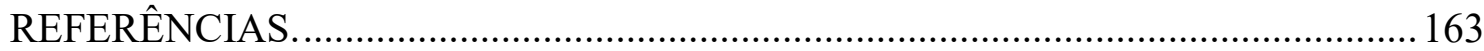

ANEXO I: Coeficientes de Participação dos Estados................................................... 175

ANEXO II: Coeficientes de Participação dos Municípios............................................. 177

ANEXO III: Ponderações de modalidades de ensino no FUNDEB ............................. 179 


\section{INTRODUÇÃO.}

O Federalismo Fiscal Brasileiro permanece em crise. Passados trinta anos de vigência da Carta Constitucional, verifica-se a persistência de antigos problemas. O mandamento constitucional de superação das desigualdades sociais e regionais carece de efetividade. Importantes iniciativas atenuaram os problemas em breves momentos de bonança econômica impulsionada por bons ventos externos e coordenadas a esforços de apoio às regiões mais necessitadas.

O conflito distributivo entre os entes subnacionais é patente, assim como a dependência destes em relação à União. Na conjuntura de crise fiscal enfrentada pelo Brasil desde 2015 até a realização deste trabalho, o Direito Financeiro assume posição primordial à reflexão dos instrumentos institucionais que carecem de aplicação ou aprimoramento.

O presente estudo tem por objeto a análise dos critérios de transferência intergovernamental de recursos por meio dos Fundos Públicos enquanto ferramenta para a superação de desigualdades sociais e regionais. Partindo-se da análise da estruturação concebida ao Federalismo Fiscal Brasileiro, verifica-se que as transferências federativas se baseiam em critérios falhos e limitados, por vezes em descompasso com o quanto previsto pela Constituição Federal.

A arrecadação fiscal visa assegurar os recursos necessários ao provimento de bens e serviços públicos à população. A gestão destes recursos, por sua vez, ocorre de formas variadas, constituindo o Orçamento elemento próprio de disputa entre as mais diversas demandas por alocação das riquezas arrecadadas. Diferentes mecanismos de controle e definição de prioridades se inserem sobre a riqueza nacional, de modo a definir como e quanto será gasto - ou não será - conforme área sócio-política, região e finalidades almejadas. Diferentes rubricas orçamentárias se inserem sob o "cobertor curto" da responsabilidade fiscal, enquanto o desequilíbrio da dívida pública impõe, por vezes, a relativização de direitos fundamentais. 
Orientando-se a interpretação do Direito Financeiro pela Constituição, a situação atual exige crítica quanto ao estado atual das prioridades orçamentárias. A análise da presente pesquisa volta-se, pois, a dois elementos principais da alocação de recursos: o sócio-político e o regional. Entendidos determinados bens e serviços públicos como instrumentos de efetivação de direitos fundamentais, o seu adequado financiamento exige a alocação suficiente do recurso público, conforme a demanda e a realidade local. Assim, o financiamento da saúde, da educação, da segurança, do saneamento, da habitação, do transporte etc., que serão chamadas áreas sócio-políticas no presente trabalho, exigem a distribuição da riqueza nacional de acordo com as mais variadas demandas e realidades, dentro da diversidade de condições econômicas de um país vasto como o Brasil.

O aprimoramento de tais mecanismos de alocação é a questão que se pretende enfrentar no presente estudo. Diante da constatação de que a forma atual de arrecadação e aplicação se orienta por critérios complexos, que muitas vezes se apresentam de forma confusa, aleatória e arbitrária, pretende-se analisar mecanismos institucionais capazes de aprimorar a forma pela qual se efetiva a aplicação da riqueza pública às áreas sóciopolíticas e às regiões do país. Visando o aprimoramento dos mecanismos de rateio e vinculação de recursos, passa-se, então à análise do mecanismo orçamentário dos Fundos Públicos.

Constituem os Fundos Públicos instrumento peculiar dentro da estrutura orçamentária, conforme será analisado. Instrumentalizam os mecanismos de aplicação vinculada e de transferência de recursos, permitindo o cálculo de critérios próprios e obrigatórios para a transferência de recursos.

Operacionalizando o rateio indireto de recursos concentrados no governo central, encontram-se os Fundos de Participação. Serão analisados seus aspectos de organização, sua atuação federativa, suas características formais e os elementos que orientam o rateio de recursos promovido. Busca-se verificar a inteligência própria de aplicação e avaliação de critérios à alocação de recursos e sua conformidade com a concepção federativa inscrita na Constituição Federal.

Em caráter diverso, os Fundos Públicos propiciam também importante mecanismo de vinculação de receita, atuando nas diferentes áreas sócio-políticas, ocasião 
em que se denominam Fundos de Destinação. Verifica-se, em tais fundos, a preocupação com a aplicação para o incremento das rubricas orçamentárias destinadas a determinada área, vinculando-se uma determinada dotação orçamentária e outras fontes de recursos para que fiquem reservados à alocação precisamente às variadas áreas sócio-políticas conforme regramento próprio definido na norma que institui e rege determinado fundo. Em tal formação, a criação de um fundo representa o prestígio político conferido a uma determinada demanda - ou, ainda, a falta de designação de uma fonte segura de recursos possa enaltecer a falta de prioridade política.

As figuras dos Fundos de Participação e dos Fundos de Destinação constituem a compreensão predominante em Direito Financeiro sobre os Fundos Públicos. Todavia, tal compreensão convencional não esgota as possibilidades de ocorrência destes instrumentos fiscais. Em virtude da demanda de transferência de recursos para diversas áreas, constata-se a possibilidade de que Fundos de Destinação incorporem também critério federativos para a transferência de recursos, integrando os diferentes níveis governamentais em torno da implementação de determinadas políticas públicas.

Em tal aspecto se verificam Fundos Públicos marcados por critérios híbridos e mais complexos, os quais constituem doutrinariamente outra classificação. Assim, pois, existe a possibilidade de atuação dos fundos para constituir a equalização de receitas, repactuando-se o equilíbrio federativo - Fundos de Equalização. Sob tal perspectiva, o sistema de fundos pode consubstanciar uma importante revisão da dinâmica de distribuição de recursos.

A partir desta constatação volta-se o presente trabalho à perspectiva oferecida pelo Fundo de Manutenção e Desenvolvimento da Educação Básica (FUNDEB), o qual introduziu a Equalização Fiscal como critério de alocação de recursos. Trata-se, no caso, de um Fundo de Destinação com critérios federativos de equidade na alocação de recursos vinculados a área da educação básica, capaz de considerar a realidade econômica local, mais que simplesmente transferir automaticamente recursos federais aos entes subnacionais.

Pela experiência verificada no FUNDEB, insere-se ao ordenamento jurídico brasileiro critérios federativos de aplicação de recursos melhor embasados na realidade 
local do ente destinatário de transferências, passando a União a atuar como ente complementar, observado um padrão mínimo nacional a ser atingido.

Analisa-se o critério federativo que orienta o mecanismo do FUNDEB e os elementos conceituais que embasam tal formulação. Busca-se, a partir da compreensão de seu funcionamento, suas deficiências e sua efetividade na aplicação de recursos, avaliar sua aplicabilidade tanto às demais áreas sócio-políticas quanto à estruturação própria do rateio federativo de recursos.

A investigação sobre as peculiaridades do FUNDEB no critério de transferência federativa parte, pois, do diagnóstico sobre a insuficiência dos critérios de alocação de recursos nas duas dimensões de atuação dos Fundos Públicos (Oliveira, 2010, p. 555): o rateio federativo e a vinculação de receitas. Tomam-se por pressupostos a finalidade de proteção da aplicação da receita pública em determinadas áreas sóciopolíticas, por intermédio da vinculação estabelecida na criação dos Fundos de Destinação, e a finalidade federativa de superação de desigualdades regionais, por meio do rateio indireto de recursos ponderado por critérios, caso dos Fundos de Participação.

Almeja o presente trabalho a compreensão desta perspectiva de aplicação de recursos, buscando o aprimoramento do Federalismo Fiscal Brasileiro e compreendendo que o instrumento dos Fundos Públicos pode contribuir para tanto. Orienta-se a presente pesquisa pelas finalidades constitucionais que devem reger a interpretação do Direito Financeiro. Busca-se refletir sobre as possibilidades econômico-orçamentárias de fortalecimento do investimento público social e de superação das desigualdades regionais. Em face das condições vigentes de distribuição federativa de recursos, insere-se, pois, o conceito de Equalização Fiscal que ofereceria melhores condições de atender às finalidades constitucionais.

Nesse sentido, um modelo de Fundos de Equalização seria caracterizado pelo estabelecimento de um patamar a ser observado por cada ente federado no emprego dos recursos a dada finalidade - seja um patamar definido de despesa, seja um patamar de receita mínima a ser complementado pelo fundo. Trata-se de um mecanismo de transferência de recursos não restrito apenas a uma distribuição arbitrária, ou pautada pela extensão populacional e inverso da renda local, como nos Fundos de Participação, mas 
que efetivamente considera a capacidade arrecadatória própria do ente destinatário da transferência. No caso do FUNDEB, por exemplo, estabelece-se um patamar mínimo de gasto por aluno ao ente federado, o qual, se não atingido pelo ente por insuficiência de recursos próprios, é complementado pelo fundo federal.

Atentando-se ao rateio federativo, poder-se-ia fixar um patamar estimado mínimo de receita estadual, ou municipal, per capita, o qual, não atingido, seria complementado por um Fundo de Equalização - possível alternativa à atual estrutura federativa dos Fundos de Participação. Eis que a análise preliminar leva à hipótese de que a distinção entre Fundos de Participação e Fundos de Destinação poderia ser superada, atuando-se federativamente em critérios mais elaborados à aplicação de recursos, somando-se o critério federativo de rateio à vinculação às diversas áreas sócio-políticas, protegendo-se nacionalmente a garantia do mínimo existencial, propiciando-se aplicação às diretrizes constitucionais de superação das desigualdades regionais e efetividade aos direitos sociais por meio da vinculação em critérios mais equânimes nacionalmente, consideradas as realidades das economias locais em um país tão vasto como o Brasil.

Diante do complexo sistema de rateio de fontes de arrecadação e do produto arrecadado, que caracteriza o Federalismo Fiscal Brasileiro, assimetrias alocativas e conflitos federativos marcam essa dinâmica e apontam à necessidade de seu aprimoramento. Destaca-se, então, como alternativa institucional que poderia melhor solucionar os conflitos federativos ora encontrados no Brasil a adoção de um modelo de Fundos de Equalização, do qual o FUNDEB é o exemplo único no ordenamento brasileiro, pelo qual as receitas transferidas pudessem ser distribuídas de modo mais justo e equilibrado entre os entes federados para o atingimento de determinada cobertura mínima de bens e serviços públicos, conforme índices previamente estabelecidos. Haveria sinergia entre vinculação sócio-política e rateio federativo, observando-se a realidade econômica local.

Pretende-se, pelo presente estudo, aprofundar tais reflexões, buscando-se o enfoque sobre os critérios vigentes que orientam a alocação federativa de recursos e sua necessária revisão para o adequado atendimento às diretrizes constitucionais. Analisar-seá, também, a conceituação dos Fundos Públicos, enquanto instrumentos à promoção da inteligência de transferência de recursos, compreendendo-se seu mecanismo de gestão, 
controle e prestação de contas e a comparação com os demais mecanismos de rateio e destinação de recursos, visando-se à incorporação da Equalização Fiscal como elemento necessário ao mecanismo.

A regra geral aos Fundos Públicos encontra-se prevista na Lei n ${ }^{\circ} 4.320 / 64$ que, em quatro artigos, prevê os denominados Fundos Especiais, entendidos como produto de receitas especificadas que por lei se vinculem à realização de determinados objetivos ou serviços, facultada a adoção de normas peculiares de aplicação de recursos e de controle, prestação e tomada de contas. A Constituição Federal, por sua vez, já prevê como instituídos ou determina a instituição de fundos, como os de Participação, os das Regiões, os Estaduais de Combate à Pobreza, dentre outros, determinando que lei complementar discipline a instituição e funcionamento de fundos.

Entendido, pois, como Fundo de Destinação dotado de critérios bem definidos de alocação federativa de recursos, será verificado o regramento do FUNDEB, como exemplo vigente de Fundo de Equalização. Nesse sentido, será analisada sua estruturação, alcançando-se a melhor compreensão acerca do conceito de Equalização Fiscal, suas diferentes formas de aplicação e sua pertinência à realidade brasileira.

Espera-se, pois, avaliar possíveis aprimoramentos aos critérios vigentes de orientação ao Federalismo Fiscal Brasileiro. A partir do instrumento dos variados Fundos de Destinação, será analisada a possibilidade de organização de uma rede de Fundos de Equalização, capazes de integrar os diferentes níveis governamentais em prol da melhor promoção dos bens e serviços públicos essenciais, instrumento elementar de efetivação de direitos fundamentais.

Parte-se, então, na presente pesquisa, de uma perspectiva da gestão físcal orientada à finalidade constitucional, verificando-se as diferentes dimensões da presença do instrumento dos Fundos Públicos, buscando-se a crítica ao alcance de seus resultados e a identificação das razões de suas insuficiências, tendo sempre por referência os elementos sócio-político e regional em que se inserem. Compreende-se que a Constituição Federal estabelece critérios mais rigorosos e elaborados à aplicação dos recursos públicos e que os fundos constituem instrumento voltado à aplicação adequada. Contudo, não se 
mostram coerentes com a perspectiva constitucional os critérios observados tanto ao rateio federativo quanto à vinculação de receitas por intermédio dos Fundos Públicos.

Os fundos podem contribuir sobremaneira ao Federalismo Fiscal Brasileiro, a fim de garantir os objetivos constitucionais de superação das desigualdades regionais e de desenvolvimento nacional. Objeto central da presente pesquisa é o aperfeiçoamento da gestão fiscal, tendo-se a experiência verificada no FUNDEB como perspectiva para aperfeiçoamento da dinâmica federativa.

O Federalismo Fiscal tem por essência a formação de distorções federativas verticais e horizontais. O regime de receitas próprias estruturado a partir de competências tributárias promove, por si, uma alteração histórica da capacidade de arrecadação de cada ente, conforme se altera o perfil econômico no tempo e no espaço. O regime de repartição de receitas, por transferência direta ou indireta, não é capaz de assegurar a necessária alocação sócio-política e regional suficiente aos objetivos constitucionais. A análise do presente trabalho se volta para tais insuficiências, buscando elementos capazes de orientar o aperfeiçoamento da distribuição federativa. A consideração do critério de Equalização Fiscal como aplicável à rede de Fundos Públicos oferece, pois, um horizonte de atingimento das finalidades constitucionais.

É certo que os Fundos de Equalização, per si, não são a solução definitiva, mas, como exposto, constituem um importante instrumento de aprimoramento da aplicação de recursos. A presente pesquisa mostra-se pertinente, pois, à análise crítica da atual situação do Federalismo Fiscal Brasileiro, com o consequente exame dos aprimoramentos possíveis à estrutura econômico-orçamentária.

Atualmente, destina-se ou rateia-se valores sem uma identificação das métricas de necessidade de tais recursos, o que poderia ser ajustado através de um sistema de Fundos de Equalização. A hipótese deste trabalho é identificar se o exemplo do FUNDEB, enquanto um Fundo de Equalização, poderia tornar mais equânime o Federalismo Fiscal Brasileiro, passando-se a um sistema voltado à proteção de uma receita mínima estimada, por ente subnacional, por habitante ou em cada área sócio-política. 
O estudo rege-se pelo método bibliográfico, orientando-se pelas mais relevantes publicações direta ou indiretamente relacionadas ao objeto definido nas áreas de Direito Financeiro, Direito Econômico, Direito Tributário, Direito Constitucional e Economia Política. Não se pretende um estudo de direito comparado, mas referências estrangeiras são utilizadas em caráter ilustrativo.

A pesquisa busca a análise dogmática, levando em consideração o conjunto normativo aplicado à atuação do Estado no e sobre o domínio econômico, à implementação de políticas públicas, ao investimento público, ao Orçamento, aos Fundos Públicos e às instituições jurídicas de natureza similar. São examinadas também as decisões judiciais de relevo ao tema. Orienta-se sempre a interpretação do texto normativo com a Constituição Federal, concebendo-se o Direito Financeiro a partir de tal perspectiva e verificando-se a conformidade do instituto analisado à ordem econômica constitucionalmente concebida e suas finalidades. 


\section{CONSIDERAÇÕES FINAIS.}

A Constituição Federal tem como referência a descentralização política paralelamente à centralização da arrecadação de recursos. As diferenças socioeconômicas por sua vez imprimem capacidades diversas de arrecadação aos governos locais. As disparidades são próprias de um país vasto e federativo. São, entretanto, exacerbadas no caso brasileiro, fruto de condições históricas. A Constituição reconhece a desigualdade e busca sua superação, consagrando a equidade como critério econômico.

Diante da concentração de recursos na União e das disparidades de arrecadação própria, os instrumentos de repartição de receitas devem promover o equilíbrio de condições econômicas. Os instrumentos financeiros para superação das desigualdades sociais e regionais existem, mas se mostram falhos e insuficientes. $\mathrm{O}$ Federalismo Fiscal Brasileiro não pode mais conviver com os critérios vigentes nos Fundos de Participação. A persistência de referenciais arbitrários e defasados não é compatível com a concepção constitucional de Federalismo Cooperativo. Tal fórmula inadequada de distribuição é ainda reproduzida no rateio de receitas de royalties e na

A superação das desigualdades sociais e regionais somente se poderá efetivar pela adequação da fórmula financeira de rateio, introduzindo-se o critério de equidade por meio da instituição de um sistema de Fundos de Equalização. A experiência verificada com o FUNDEB demonstra que é compatível com o ordenamento jurídico-financeiro do país a adaptação do mecanismo para adequação das transferências intergovernamentais, passando a se orientar pela mensuração de necessidades fiscais e demandas sociais.

Superando-se o mero rateio federativo, pode-se promover a integração federativa nas áreas sócio-políticas prioritárias definidas. O rol constitucional de competência comum oferece indicativo de por onde se deve orientar a implementação dos Fundos de Equalização.

A verdadeira cooperação federativa só pode ser exercida mediante revisão do critério de rateio federativo e aprimoramento das transferências obrigatórias. Concatenando-se transferências vinculadas, pode-se ampliar a integração entre os três 
níveis governamentais para a implementação de políticas públicas, orientando-se pela garantia de uma oferta mínima nacional de bens e serviços nas áreas sócio-políticas definidas, promovendo-se, pois, uma cesta básica de serviços públicos voltada à garantia do mínimo existencial que reafirme a cidadania é a mesma em todo o território nacional nenhum brasileiro é menos titular de direitos fundamentais conforme a localidade de seu nascimento ou moradia.

O mecanismo dos Fundos Públicos mostra-se pertinente para operacionalizar um sistema de vinculações e transferências obrigatórias condicionadas, assegurando-se a observância da implementação das políticas almejadas e manutenção da vinculação através da garantia de preservação do saldo. Também por meio dos Fundos Públicos segregam-se adequadamente os recursos para a aplicação da fórmula de rateio, sobre a qual, com a implementação dos Fundos de Equalização, se passaria a computar as necessidades fiscais e demandas sociais locais. Ampliar-se-ia a complexidade da fórmula, devendo o fundo contar com estrutura gestora, seja do próprio Tribunal de Contas, como verificado nos Fundos de Participação, seja um conselho próprio para avaliação da área sócio-política contemplada, como no caso do FUNDEB.

O aprimoramento dos critérios para transferências, contudo, não basta. A efetividade dos Fundos de Equalização depende da garantia de preservação das vinculações e formação da cesta básica de serviços públicos. Expedientes como a Desvinculação de Receitas, teto de gastos e contingenciamento devem ser afastados das receitas destinadas aos Fundos de Equalização.

A decisão do Supremo Tribunal Federal na ADPF $n^{\circ} 347$, deve orientar o alcance da incidência dos instrumentos de responsabilidade fiscal sobre as áreas sóciopolíticas prioritárias. Não se pode aguardar que uma crise na oferta de leitos hospitalares ou de vagas em creches, ou um novo surto na área penitenciária e de segurança pública seja necessária para nova declaração sobre um estado de coisas inconstitucional, a ensejar o afastamento da desvinculação de receitas ou do teto de gastos, à semelhança do quanto decido sobre o contingenciamento.

A implementação de um sistema de Fundos de Equalização deve orientar-se, portanto, (i) pela efetiva superação das desigualdades regionais através do aprimoramento 
dos critérios federativos de transferências intergovernamentais, passando-se a identificar as efetivas necessidades fiscais e demandas sociais por complementação da receita local; (ii) pela efetivação de direitos fundamentais através da garantia do mínimo existencial pelo estabelecimento de padrões elementares nacionais a serem observados na oferta de bens e serviços públicos, formulando-se uma cesta básica de serviços a ser implementada pelos três níveis governamentais, reunindo-se recursos vinculados não contingenciáveis operacionalizados pela rede de fundos voltados a transferências obrigatórias e condicionadas à implementação das políticas públicas essenciais.

Orientados pelo objetivo de superação das desigualdades sociais e regionais, destacamos dentre os desafios do Federalismo Fiscal Brasileiro a adequada repartição das fontes e do produto da arrecadação. Buscamos, pois, a melhor referência de critério de alocação de recursos, através da experiência do FUNDEB, chegando-se à aplicabilidade do modelo para todo o sistema federativo.

Os desafios não se esgotam por aí. Temas que ficaram fora do escopo do presente trabalho como a efetivação de renúncias fiscais em receitas sujeitas ao compartilhamento federativo, o aprimoramento do mecanismo de compartilhamento da arrecadação do ICMS em operações interestaduais e o endividamento dos entes subnacionais são também grandes questões a serem enfrentadas pelo Federalismo Cooperativo e que podem encontrar no sistema de Fundos de Equalização parte da solução. O cerne da discussão reside no aprimoramento das relações federativas, de modo a que a equidade oriente os critérios de compartilhamento de receitas, efetivando-se o Federalismo Cooperativo.

Por fim, ainda que ampla a compreensão acerca da presença da equidade como critério a orientar as relações do Federalismo Cooperativo, mostra-se cabível a reflexão acerca da forma de rateio pela qual se orientam os Fundos de Equalização. Críticos podem alegar que tal modelo premiaria a ineficiência, vez que privilegia justamente os entes que menos arrecadam e que menos demonstram condições de oferecer, pelas condições locais, a adequada oferta bens e serviços públicos.

Ao supostamente premiar a ineficiência, o modelo seria promotor da dependência dos entes subnacionais, que passariam a ver nos Fundos de Equalização uma 
fonte segura de recursos, deixando de almejar a arrecadação satisfatória de recursos, capaz de consagrar a efetiva autonomia política e financeira.

A crítica é pertinente na medida em que critérios mal formulados para a equalização podem, de fato, favorecer que os entes subnacionais se utilizem de renúncias fiscais, da defasagem de alíquotas ou até mesma da ineficiência na arrecadação de modo a favorecer determinadas atividades em seu território, negligenciando a arrecadação necessária ao financiamento de suas atividades, contando com a receita transferida.

Entretanto, não é a Equalização Fiscal que compromete a arrecadação local e gera tal dependência política e financeira. Deve-se, primeiramente, levar a sério as disparidades regionais. O volume e a complexidade da atividade econômica são efetivamente díspares conforme a localidade do país, o que não decorre da negligência de seus governos em promover determinadas iniciativas em prol da arrecadação. Pelo contrário, a ânsia em atrair atividade econômica é que gera verdadeira corrida entre os entes subnacionais pela promoção de renúncias fiscais. As transferências na forma vigente, por sua vez, encaram a dependência de diversos entes por recursos sem que o critério de Equalização Fiscal esteja presente.

O que de fato se verifica é que a dependência de receita transferida decorre da realidade econômica. As diferenças de matrizes econômicas locais face às competências tributárias instituídas, a concentração da arrecadação no governo central, a presença ou proximidade de reservas de recursos naturais exploráveis, além de fatores históricos, demográficos e geográficos implicam, invariavelmente, em disparidades na capacidade de arrecadação. Ainda que não se trata-se no caso brasileiro de país tão desigual socialmente, algum nível de disparidade na capacidade de arrecadação é próprio do sistema federativo, mostrando-se pertinente a equalização para a correção de tais assimetrias intrínsecas ao modelo.

A forma de se evitar os efeitos perversos decorrentes do modelo de rateio de recursos orientado aos entes menos favorecidos economicamente consiste precisamente na adequada fixação de critérios de mensuração das capacidades e das necessidades fiscais. Nesse sentido, não se pode apenas avaliar a arrecadação local percebida, mas a arrecadação potencial, por exemplo, afastando-se deste cômputo os efeitos decorrentes 
das renúncias fiscais inerentes à autonomia política e financeira local. A complementação federal deve orientar-se por critérios objetivos que assegurem a observância dos padrões mínimos nacionais no provimento de bens e serviços públicos, consagrando a equidade como elemento próprio do Federalismo Cooperativo.

A implementação da Equalização Fiscal mostra-se, portanto, plenamente viável e factível ao Federalismo Fiscal Brasileiro, constituindo o instrumento adequado para a efetividade dos objetivos de superação das desigualdades regionais. A reforma é urgente. 


\section{REFERÊNCIAS.}

Abrucio, Fernando Luiz. A dinâmica federativa da educação brasileira: dignóstico e propostas de aperfeiçoamento. Em Educação e Federalismo no Brasil: combater as desigualdades, garantir a diversidade, por Romualdo Portela de Oliveira e Wagner Santana, 39-70. Brasília: Unesco, 2010.

Andrade, José Maria Arruda de. Normas gerais, nacionais, competência legislativa e o federalismo fiscal. In: Revista Brasileira de Estudos Constitucionais, Belo Horizonte, v. 2, n. 6, p. 67-86, abr./jun. 2008.

Araújo, Raimundo Luiz Silva. Limites e possibilidades da redução das desigualdades territoriais por meio do financiamento da educação básica. São Paulo: Universidade de São Paulo, 2013.

Arelaro, Lisete, e Juca Gil. Política de fundos na educação: duas posições. Em Fundeb: Fundo de Manutenção e Desenvolvimento da Educação Básica e de Valorização dos Profissionais da Educação: avanços na universalização da educação básica, por Vital Didonet e Maria José Rocha Lima, 71-88. Brasília: Instituto Nacional de Estudos e Pesquisas Educacionais Anísio Teixeira, 2006.

Assunção, Matheus Carneiro. Repartição das receitas tributárias no federalismo fiscal brasileiro: os critérios de rateio dos fundos de participação. Dissertação de Mestrado. Orientador Prof. Associado Dr. Fernando Facury Scaff. São Paulo: Faculdade de Direito da Universidade de São Paulo, 2013.

Ataliba, Geraldo. Apontamentos de ciência das finanças, direito financeiro e tributário. São Paulo: RT, 1969.

Avelãs Nunes, António José; Scaff, Fernando Facury. Os tribunais e o direito à saúde. Porto Alegre: Editora Livraria do Advogado, 2011.

Ávila, Humberto. Sistema Constitucional Tributário. 4a ed. São Paulo: Saraiva, 2010. 
Azevedo Neto, Evandro. Guerra fiscal: a renúncia de receita e suas glosas no federalismo fiscal brasileiro. Dissertação de Mestrado. Orientador Prof. Associado Dr. Fernando Facury Scaff. São Paulo: Faculdade de Direito da Universidade de São Paulo, 2015.

Baleeiro, Aliomar; Derzi, Misabel Abreu Machado. Direito Tributário Brasileiro. Atualização de Misabel Abreu Machado Derzi. Rio de Janeiro: Forense, 1999.

Barreto, Paulo Ayres. Contribuições: regime jurídico, destinação e controle. São Paulo: Noeses, 2006.

Becker, Alfredo Augusto. Teoria Geral do Direito Tributário. $2^{\mathrm{a}}$ ed. São Paulo: Saraiva, 1972.

Béland, Daniel, e André Lecours. Federalism and Fiscal Policy: The Politics of Equalization in Canada. Publius. The Journal of Federalism. Vol. 40, no 4 (Fall 2010): 569-596.

Bercovici, Gilberto (Org.). Elementos de direito da infraestrutura. São Paulo: Contracorrente, 2015.

Bercovici, Gilberto. Desigualdades regionais, Estado e Constituição. São Paulo: Max Limonad, 2003.

Bercovici, Gilberto. Direito Econômico do petróleo e dos recursos minerais. São Paulo: Quartier Latin, 2011.

Bercovici, Gilberto; Massonetto, Luís Fernando. A Constituição dirigente invertida: a blindagem da constituição financeira e a agonia da constituição econômica. In: Boletim de Ciências Econômicas XLIX. Coimbra, 2006.

Bliacheriene, Ana Carla; Lucena, Elisa Vanzella de; Braga, Marcos Vinicius de Azevedo; Oliveira Junior, Temistocles Murilo de. Descentralização do Fundeb e federalismo da 
política educacional: uma análise à luz do conceito de accountability. Jornal de Política Educacionais 10 (julho-dezembro 2016): 33-48.

Boadway, Robin; Shah, Anwar. Fiscal Federalism: Principles and Practices of Multiorder Governance. New York: Cambridge University Press, 2009.

Borges, José Souto Maior. Introdução ao Direito Financeiro. São Paulo: Max Limonad, 1998.

Brasil. FNDE - Ministério da Educação. FNDE repassa R\$ 963 milhões da complementação da União. Publicado em 28 de maio de 2018. Último acesso em 20 de dezembro de 2018. https://www.fnde.gov.br/acesso-a-informacao/institucional/area-deimprensa/noticias/item/11889-fnde-repassa-r\$-963-milh\%C3\%B5es-dacomplementa $\% \mathrm{C} 3 \% \mathrm{~A} 7 \% \mathrm{C} 3 \% \mathrm{~A} 30-$ da-uni $\% \mathrm{C} 3 \% \mathrm{~A} 30-\mathrm{ao}-$ fundeb.

Buchanan, James. Federalism and Fiscal Equity. The American Economic Review (American Economic Association) Vol 40, nº N. 4 (1950): 583-599.

Carraza, Roque Antônio. Curso de Direito Constitucional Tributário. São Paulo: Malheiros, 2010.

Carvalho, André Castro. Direito da Infraestrutura. Perspectiva Pública. São Paulo: Quartier Latin, 2014.

Carvalho, André Castro. Vinculação de receitas públicas e princípio da não-afetação: usos e mitigações. Dissertação de Mestrado. Orientador Prof. Associado José Maurício Conti. São Paulo: Faculdade de Direito da Universidade de São Paulo, 2010.

Carvalho, José Augusto Moreira de. O federalismo fiscal brasileiro e o desvio de recursos. Tese de Doutorado. Orientador Prof. Titular Regis Fernandes de Oliveira. São Paulo: Faculdade de Direito da Universidade de São Paulo, 2010.

Carvalho, Laura. Valsa brasileira: do boom ao caos econômico. Todavia: São Paulo, 2018. 
Carvalho, Paulo de Barros. Curso de Direito Tributário. 23 ed. São Paulo: Saraiva, 2011.

Caselli, Bruno Conde. O Pré-Sal e as mudanças da regulação da indústria do petróleo e gás natural no Brasil: uma visão institucional. Revista Brasileira de Direito Público - RBDP. Belo Horizonte: Fórum, ano 9, n. 35, P. 111-140.

Conti, José Maurício (Org.). Federalismo fiscal. São Paulo: Manole, 2004.

Conti, José Maurício. Considerações sobre o federalismo fiscal brasileiro em uma perspectiva comparada. Em Federalismo Fiscal, questões contemporâneas, por José Maurício Conti, Fernando Facury Scaff e Carlos Braga, 15-34. São José: Conceito, 2010.

Conti, José Maurício. Federalismo Fiscal e Fundos de Participação. São Paulo: Juarez de Freitas, 2001.

Conti, José Maurício. Levando o Direito Financeiro a Sério. São Paulo: Blucher, 2016.

Conti, José Maurício. Lochagin, Gabriel. Federalismo fiscal brasileiro e o novo FPE (Fundo de Participação dos Estados e do Distrito Federal). In: Raquel Elita Alves Preto (Organização). Tributação brasileira em evolução: estudos em homenagem ao Professor Alcides Jorge Costa, São Paulo: Editora IASP, 2015. P. 53-69.

Conti, José Maurício; Scaff, Fernando Facury. Orçamentos públicos e direito financeiro. São Paulo: Revista dos Tribunais, 2011.

Conti, José Maurício; Scaff, Fernando Facury; Braga, Carlos Eduardo Faraco (Organizadores). Federalismo fiscal: questões contemporâneas. São José, SC: Conceito Editorial, 2010.

Craig, Jon. Australia (Fiscal Federalism in Theory and Practice). Em Fiscal Federalism in Theory and Practice, por Teresa Ter-Minassian, 3352-3781. Washington DC.: International Monetary Fund (Amazon/Kindle version), 1997. 
Dallari, Dalmo. Elementos de Teoria Geral do Estado. 2. ed. São Paulo: Saraiva, 1998.

Derzi, Misabel Abreu Machado, e Aliomar Baleeiro. Limitações Constitucionais ao Poder de Tributar. Rio de Janeiro: Forense, 1997.

Farina, Milton Carlos. Gouvêa, Maria Aparecida. Varela, Patrícia Siqueira. Equalização Fiscal: Análise do Fundo de Participação dos Municípios com o Uso de Regressão Logística. Organizações em contexto, ano 4, n. 8, dezembro de 2008.

Fernandes, Andressa Guimarães Torquato. Direito financeiro aplicado ao setor de petróleo. Tese de Doutorado. Orientador Prof. Associado Dr. José Maurício Conti. São Paulo: Faculdade de Direito da Universidade de São Paulo, 2013.

Ferraz Junior, Tercio Sampaio Ferraz. Introdução ao Estudo do Direito: técnica, decisão, dominação. $6^{\mathrm{a}}$ ed. São Paulo: Atlas, 2010.

Föttinger, Wolfgand; Spahn, Paul Bernard. Germany (Fiscal Federalism in Theory and Practice). Em Fiscal Federalism in Theory and Practice, por Teresa Ter-Minassian, 4219-4615. Washington D.C.: International Monetary Fund (Amazon/Kindle version), 1997.

Francisco Neto, João. Responsabilidade fiscal e gasto público no contexto federativo. Tese de Doutorado. Orientador Prof. Titular Regis Fernandes de Oliveira. São Paulo: Faculdade de Direito da Universidade de São Paulo, 2009.

Furtado, Celso. Formação Econômica do Brasil. 34. Ed. São Paulo: Cia. Das Letras, 2007.

Giacomoni, James. Receitas vinculadas, despesas obrigatórias e rigidez orçamentária. Em Orçamentos públicos e direito financeiro, por José Maurício Conti e Fernando Facury Scaff (coord.), 1342. São Paulo: Revista dos Tribunais, 2011.

Giacomoni, James. Orçamento Público. $16^{\mathrm{a}}$ ed. Ampliada, revista e atualizada. São Paulo: Atlas, 2012. 
Grau, Eros Roberto. A ordem econômica na Constituição de 1988. 15 $5^{\mathrm{a}}$ ed. Revista e atualizada. São Paulo: Malheiros, 2012.

Haber Neto, Michel. A tributação e o financiamento do direito à saúde no Brasil. Dissertação de Mestrado. Orientador Prof. Associado Dr. Fernando Facury Scaff. São Paulo: Faculdade de Direito da Universidade de São Paulo, 2012.

Holmes, Stephen; Sunstein, Cass R. The cost of rights. Why liberty depends on taxes. New York, United States of America: WW Norton \& Company, 2000.

Krelove, Russell, Janet Stotsky, e Charles Vehorn. Canada (Fiscal Federalism in Thoery and Practice). Em Fiscal Federalism in Thoery and Practice, por Teresa Ter-Minassian, 3782-4218. Washington: International Monetary Fund (Amazon/Kindle version), 1997.

Limonti, Rogério Machado, Ursula Dias Peres, e Eduardo de Lima Caldas. Política de fundos na educação e desigualdades municipais no estado de São Paulo: uma análise a partir das arenas políticas de Lowi. Rev. Adm. Pública, 1 de mar./abr. de 2014: 389-409.

Lobo, Rogério Leite. Federalismo fiscal brasileiro: discriminação das rendas tributárias e centralidade normativa. Rio de Janeiro: Lumen Juris, 2006.

Lochagin, Gabriel Loretto. A flexibilidade da execução orçamentária. Dissertação de Mestrado. Orientador Prof. Associado Dr. José Maurício Conti. São Paulo: Faculdade de Direito da Universidade de São Paulo, 2012.

Lochagin, Gabriel Loretto. Elementos jurídicos da reestruturação internacional da dívida pública. Tese de Doutorado. Orientador Prof. Associado Dr. José Maurício Conti. São Paulo: Faculdade de Direito da Universidade de São Paulo, 2016.

Martins, Ives Gandra Da Silva. Mendes, Gilmar Ferreira. Nascimento, Carlos Valder do (Org.). Tratado de Direito Financeiro. São Paulo: Saraiva, 2013.

Meireles, Hely Lopes. Finanças Municipais. São Paulo: RT, 1979. 
Mello, Celso Antônio Bandeira. Curso de Direito Administrativo. $32^{\mathrm{a}}$ ed. São Paulo: Malheiros Editores, 2015.

Musgrave, Richard. Approaches to a Fiscal Theory of Political Federalism. Em Wallace Oates (Org.), The Economics of Fiscal Federalism and Local Finance (pp. 187212). Northampton: Edward Elgar Publishing, 1998.

Nogueira, Ruy Barbosa. Curso de Direito Tributário. 14ª ed. São Paulo: Saraiva, 1995.

Nunes, Antônio José Avelãs. Uma introdução à Economia Política. São Paulo: Quartier Latin, 2007.

Oates, Wallace E. (Editor). The economics of fiscal federalism and local finance. Cheltenham, United Kingdom: Edward Elgar, 1998.

Oliveira, Regis Fernandes de. Curso de Direito Financeiro. $7^{\text {a }}$ ed. São Paulo: RT, 2015.

Oliveira, Ricardo Victalino de. A configuração assimétrica do federalismo brasileiro. Dissertação de Mestrado. Orientador Prof. Titular Fernando Dias Menezes de Almeida. São Paulo: Faculdade de Direito da Universidade de São Paulo, 2010.

Pires, Adilson Rodrigues. Tôrres, Heleno Taveira (Organizadores). Princípios de direito financeiro e tributário: estudos em homenagem ao professor Ricardo Lobo Torres. Rio de Janeiro; São Paulo: Renovar, 2006.

Prado, Sergio (Coord.). Partilha de recursos na Federação Brasileira. São Paulo: FAPESP. Edições FUNDAP. Brasília: IPEA, 2003.

Prado, Sergio. Equalização e federalismo fiscal: uma análise comparada. KonradAdenauer-Stiftung, 2006.

Preto, Raquel Elita Alves. Da Competência à Sujeição Ativa Tributária. Tese de Doutorado. Orientador Prof. Dr. Paulo Celso Bergstrom Bonilha. São Paulo: Faculdade de Direito da Universidade de São Paulo, 2008. 
Rezende, Fernando. Federalismo Fiscal: em busca de um novo modelo. Em Educação e Federalismo no Brasil: combater as desigualdades, garantir a diversidade, por Romualdo Portela de Oliveira e Wagner Santana, 71-88. Brasília: Unesco, 2010.

Rocha, Fabiana. Novas Regras de Partilha do FPE: Uma Reflexão. Informações FIPE, 30 de abril de 2013, no 391 ed.: 30.

Rodrigues, Flávio Martins. Fundos de pensão de servidores públicos. Rio de Janeiro: Renovar, 2002.

Rubinstein, Flávio. Promoção da Equalização Fiscal no Federalismo Brasileiro: o Papel dos Fundos de Participação. Em Federalismo Fiscal: Questões contemporâneas, por José Mauricio Conti, Fernando Facury Scaff e Carlos Eduardo Faraco Braga, 243-284. Florianópolis: Conceito, 2010.

Rubinstein, Flávio. Receitas Públicas de Recursos Naturais no Direito Financeiro Brasileiro. Tese de Doutorado. Orientador Prof. Titular Regis Fernandes de Oliveira. São Paulo: Faculdade de Direito da Universidade de São Paulo, 2012.

Sanches, Osvaldo Maldonado. Novo Dicionário de Orçamento e Áreas Afins. Brasília: Osvaldo Maldonado Sanches, 2013.

Santos, Homero. Fundos Federais. Revista do Tribunal de Contas da União, 1992: 2129.

Santos, Ricart César Coelho dos Santos. Os Fundos de Saúde e o Financiamento do Sistema Único de Saúde no Brasil. Dissertação de Mestrado. Orientador Professor Titular Regis Fernandes de Oliveira. São Paulo: Faculdade de Direito da Universidade de São Paulo, 2015.

Scaff, Fernando Facury. Direito tributário e financeiro aplicado. São Paulo: Quartier Latin, 2010. 
Scaff, Fernando Facury. Disputas Federativas, Confaz e royalties do petróleo. São Paulo: Consultor Jurídico, 2012. Disponível em:<http://www.conjur.com.br/2012-dez04/contas-vista-disputas-federativas-confaz-royalties-petroleo>

Scaff, Fernando Facury. Do Estado fiscal ao Estado endividado na sociedade desejante. São Paulo: Consultor Jurídico, 2016. Disponível em: $<$ http://www.conjur.com.br/2016-jun-14/contas-vista-estado-fiscal-estado-endividadosociedade-desejante>

Scaff, Fernando Facury. Equilíbrio orçamentário e sustentabilidade financeira e justiça intergeracional. In: Boletim de Ciências Económicas: homenagem ao prof. doutor António José Avelãs Nunes, v. 57, n. 3, p. 3179-3202, 2014.

Scaff, Fernando Facury. Federalismo fiscal cooperativo no Brasil. In: Leite, George Salomão; Leite, Glauco Salomão; Sarlet, Ingo Wolfgang; Streck, Lenio Luiz. (Coordenadores). Ontem, os códigos! Hoje, as constituições!: Homenagem a Paulo Bonavides, São Paulo : Malheiros, 2016. pp. 106-122.

Scaff, Fernando Facury. Federalismo fiscal e taxas decorrentes do poder de polícia sobre a atividade minerária. In: Tôrres, Heleno Taveira; Maneira, Eduardo (Coordenadores) Direito tributário e a constituição: homenagem ao Professor Sacha Calmon Navarro Coêlho. São Paulo: Quartier Latin, 2012. P. 283-305.

Scaff, Fernando Facury. O que vale mais: a constituição ou o anexo de metas fiscais da LRF? São Paulo: Consultor Jurídico, 2016. Disponível em: $<$ http://www.conjur.com.br/2016-nov-29/contas-vista-vale-constituicao-ou-anexometas-fiscais-lrf $>$

Scaff, Fernando Facury. Orçamento público, direitos sociais e escolhas políticas ou reserva do possível e escolhas trágicas na implementação dos direitos sociais. In: De Lucca, Newton; Meyer-Pflug, Samantha Ribeiro; Neves, Mariana Barboza Baeta (Coords.). Direito constitucional contemporâneo: homenagem ao professor Michel Temer. São Paulo: Quartier Latin, 2012. 
Scaff, Fernando Facury. Orçamento Republicano e Liberdade Igual - Ensaio sobre Direito Financeiro, República e Direitos Fundamentais no Brasil. Belo Horizonte: Fórum, 2018.

Scaff, Fernando Facury. Royalties de petróleo, minério e energia. Aspectos Constitucionais, Financeiros e Tributários. São Paulo: Ed. Revista dos Tribunais, 2014.

Schoueri, Luis Eduardo. Direito Tributário. 3ª ed. São Paulo: Saraiva, 2013.

Shah, Anwar. A Fiscal Needs Approach to Equalization Transfers in a Decentralized Federation. Washington D.C.: World Bank, 1994.

Shah, Anwar; Kincaid, John (Editors). The practice of fiscal federalism: comparative perspectives. Published for Forum of Federations/Forum des fédérations and iacfs. Montréal, Canadá: McGill-Queen’s University Press, 2007.

Silva, José Afonso da. Curso de Direito Constitucional Positivo. $35^{\text {a }}$ ed. São Paulo: Malheiros, 2011.

Silveira, Alexandre Coutinho da. Governança pública de royalties: federalismo fiscal e futuras gerações. Dissertação de Mestrado. Orientador Prof. Associado Fernando Facury Scaff. São Paulo: Faculdade de Direito da Universidade de São Paulo, 2014.

Silveira, Francisco Secaf Alves. A concretização do direito financeiro: os efeitos do contingenciamento na execução orçamentária. Dissertação de Mestrado. Orientador Prof. Associado Dr. Fernando Facury Scaff. São Paulo: Faculdade de Direito da Universidade de São Paulo, 2014.

Siqueira, Rodrigo Panizza. A política fiscal dos municípios como instrumento de controle e dominação pelo poder central. Dissertação de Mestrado. Orientador Prof. Titular Regis Fernandes de Oliveira. São Paulo: Faculdade de Direito da Universidade de São Paulo, 2015.

Soldi, Rodrigo. Desenvolvimento regional: retomada do projeto político constitucional? Saarbrücken: Novas Edições Acadêmicas, 2016 
Souza, Silas Cardoso de. As Entidades Fechadas de Previdência Complementar Enquanto Instrumentos de Atuação do Estado na Economia. Dissertação de Mestrado. Orientador Professor Dr. Luís Fernando Massonetto. São Paulo: Faculdade de Direito da Universidade de São Paulo, 2015.

Streeck, Wolfgang. Buying Time: The Delayed Crisis of Democratic Capitalism. $2^{\text {a }}$ Ed. Verso: New York, 2017 (Amazon/Kindle version).

Ter-Minassian, Teresa (Editor). Fiscal federalism in theory and practice. WashingtonDC, United States of America: International Monetary Fund, 1997.

Ter-Minassian, Teresa. Reforma do Fundo de Participação dos Estados (FPE). Divisão de Gestão Fiscal e Municipal, Brasília: Banco Interamericano de Desenvolvimento, 2012.

Torres, Heleno Taveira. A compensação financeira devida na exploração de petróleo e recursos minerais e na geração e receita petrolífera. Revista de Direito Tributário, São Paulo: Malheiros, 74, pp. 52-89.

Torres, Heleno Taveira. Constituição financeira e o federalismo financeiro cooperativo equilibrado brasileiro. In: Revista Fórum de Direito Financeiro e Econômico: RFDFE, Belo Horizonte, v. 3, n. 5, p. 25-54, mar./ago. 2014.

Torres, Heleno Taveira. Direito Constitucional Financeiro. Teoria da Constituição Financeira. São Paulo: Editora Revista dos Tribunais, 2014.

Torres, Heleno Taveira. Direito Constitucional Tributário e Segurança Jurídica. Metódica da Segurança Jurídica do Sistema Constitucional Tributário. 2a Ed. São Paulo: Editora Revista dos Tribunais, 2012.

Tôrres, Heleno Taveira. Direitos fundamentais e conflitos de competências tributárias no federalismo fiscal brasileiro: o caso dos municípios. In: Revista Fórum de Direito Tributário, Belo Horizonte, v. 6, n. 33, p. 53-86, maio/jun. 2008. 
Torres, Heleno Taveira. Os desafios do federalismo fiscal e a reforma do ICMS. In: Raquel Elita Alves Preto (Organização). Tributação brasileira em evolução: estudos em homenagem ao Professor Alcides Jorge Costa, São Paulo: Editora IASP, 2015. P. 115137.

Torres, Heleno Taveira. Reformas do federalismo fiscal avançam no Brasil. São Paulo: Consultor Jurídico, 2015. Disponível em: <http://www.conjur.com.br/2015-ago12/consultor-tributario-reformas-federalismo-fiscal-avancam-brasil?imprimir $=1>$

Torres, Heleno Taveira. Relação entre constituição financeira e constituição econômica. In: Revista Internacional de Direito Público: RIDP, Belo Horizonte, v. 1, n. 1, p. 11-21, jul./dez. 2015.

Torres, Heleno Taveira. Rodrigues, Felipe da Cunha. Fundo Soberano do Brasil - Regime jurídico dos fundos públicos especiais, experiência internacional e a Lei 11.887/2008. Belo Horizonte: Fórum, 2012.

Torres, Ricardo Lobo. Curso de Direito Financeiro e Tributário. 13 ${ }^{\mathrm{a}}$ ed. Rio de Janeiro: Renovar, 2006.

Vasconcellos, Marcos de. Governo usa bilhões do Fundo de Defesa dos Direitos Difusos para inflar o caixa. Sítio da internet Consultor Jurídico. 31 de março de 2017. Disponível em http://www.conjur.com.br/2017-mar-31/governo-usa-dinheiro-fundodireitos-difusos-caixa 
ANEXO I: Coeficientes de Participação dos Estados.

\begin{tabular}{|c|c|}
\hline Acre & 3,4210 \\
\hline Amapá & 3,4120 \\
\hline Amazonas & 2,7904 \\
\hline Pará & 6,1120 \\
\hline Rondônia & 2,8156 \\
\hline Roraima & 2,4807 \\
\hline Tocantins & 4,3400 \\
\hline Alagoas & 4,1601 \\
\hline Bahia & 9,3962 \\
\hline Ceará & 7,3369 \\
\hline Maranhão & 7,2182 \\
\hline Paraíba & 4,7889 \\
\hline Pernambuco & 6,9002 \\
\hline Piauí & 4,3214 \\
\hline Rio Grande do Norte & 4,1779 \\
\hline Sergipe & $.4,1553$ \\
\hline
\end{tabular}




\begin{tabular}{|c|c|}
\hline Distrito Federal & 0,6902 \\
\hline Goiás & 2,8431 \\
\hline Mato Grosso & 2,3079 \\
\hline Mato Grosso do Sul & 1,3320 \\
\hline Espírito Santo & 1,5000 \\
\hline Minas Gerais & 4,4545 \\
\hline Rio de Janeiro & 1,5277 \\
\hline São Paulo & 1,0000 \\
\hline Paraná & 2,8832 \\
\hline Rio Grande do Sul & 2,3548 \\
\hline Santa Catarina & 1,2798 \\
\hline
\end{tabular}

- Anexo Único à Lei Complementar nº 62/1989 


\section{ANEXO II: Coeficientes de Participação dos Municípios}

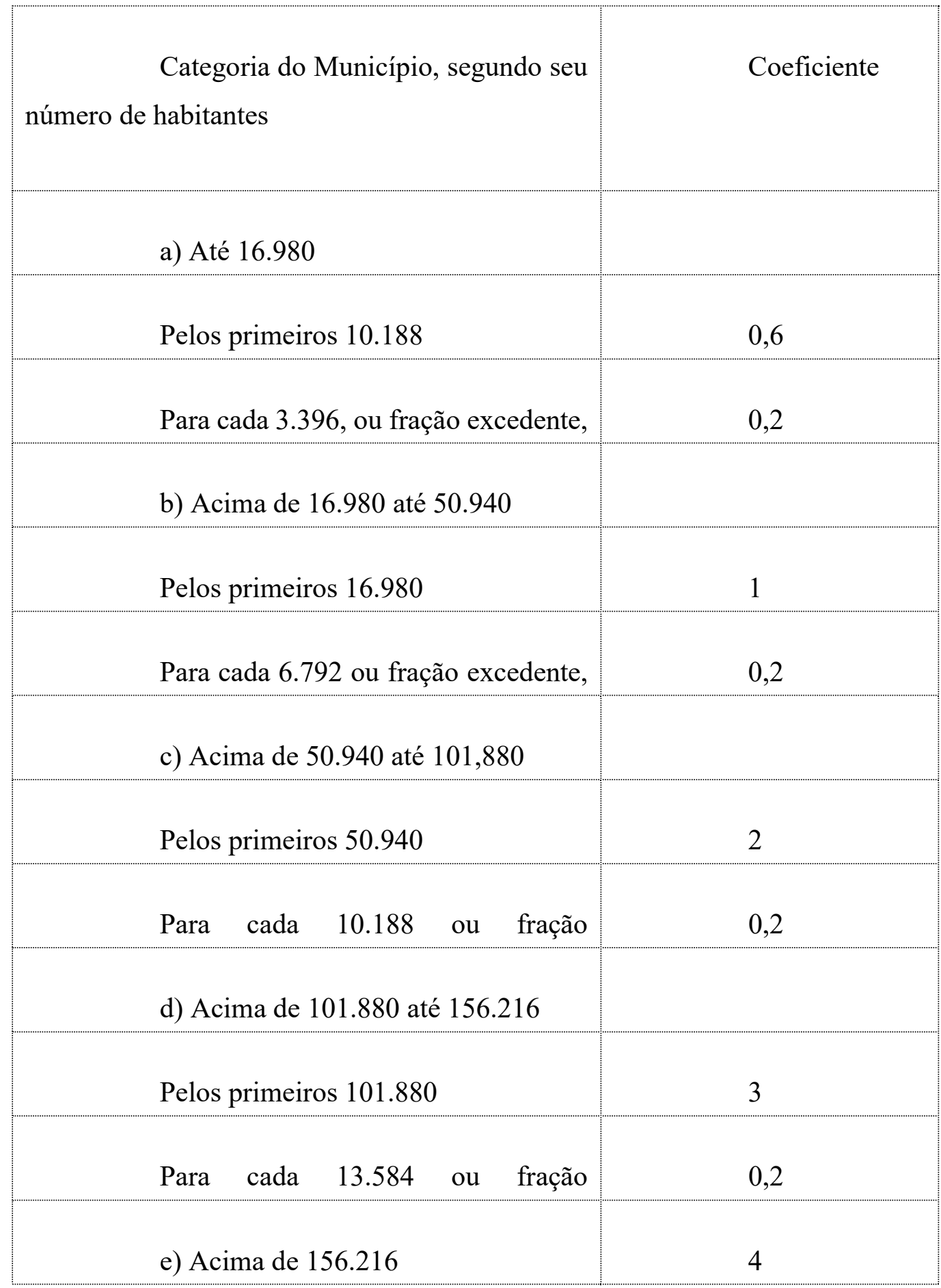

- Código Tributário Nacional, Lei $\mathrm{n}^{\circ}$ 5.172/66, art. 91, $\S 2^{\circ}$, conforme redação dada pelo Decreto Lei $n^{\circ} 1.881 / 81$. 


\section{ANEXO III: Ponderações de modalidades de ensino no FUNDEB}

\begin{tabular}{|c|c|}
\hline Modalidade de Ensino & Fator de Ponderação \\
\hline I - creche & 0,80 \\
\hline II - pré-escola & 0,90 \\
\hline III - anos iniciais do ensino fundamental urbano & 1,00 \\
\hline IV - anos iniciais do ensino fundamental no campo & 1,05 \\
\hline $\mathrm{V}$ - anos finais do ensino fundamental urbano & 1,10 \\
\hline VI - anos finais do ensino fundamental no campo & 1,15 \\
\hline VII - ensino fundamental em tempo integral & 1,25 \\
\hline VIII - ensino médio urbano & 1,20 \\
\hline IX - ensino médio no campo & 1,25 \\
\hline $\mathrm{X}$ - ensino médio em tempo integral & 1,30 \\
\hline $\begin{array}{l}\text { XI - ensino médio integrado à educação } \\
\text { profissional }\end{array}$ & 1,30 \\
\hline XII - educação especial & 1,20 \\
\hline
\end{tabular}




\begin{tabular}{|l|l|}
\hline XIII - educação indígena e quilombola & 1,20 \\
\hline XIV - educação de jovens e adultos com avaliação & 0,70 \\
\hline no processo & \\
\hline XV - educação de jovens e adultos integrada à & 0,70 \\
\hline educação profissional de nível médio, com & \\
\hline avaliação no processo & \\
\hline Na fixação dos valores a partir do $2^{\circ}$ (segundo) & ano de vigência do FUNDEB, as \\
\hline ponderações entre as matrículas da educação infantil seguirão, no mínimo, as seguintes \\
\hline pontuações:
\end{tabular}

- $\quad$ Lei n ${ }^{\circ} 11.494 / 2007$, art. 36. 